DOSIER

\title{
Aquí y ahora: la deixis en los epitafios de la Grecia clásica
}

\section{Here and Now: Deixis in the Epitaphs of \\ Classical Greece}

Evelia Arteaga Conde*

Universidad Autónoma de la Ciudad de México, México evelia.arteaga@uacm.edu.mx 


\title{
Resumen
}

En este texto se analizará la forma en que los elementos deícticos, específicamente los de lugar (aquí) y tiempo (ahora), influyen para que algunos epitafios de la región ática, de la época clásica, sean considerados una representación de un "acto de habla"; es decir, cada vez que se leen se vuelve a presentar un acto comunicativo en un contexto determinado, con la presencia de tres elementos: emisor, receptor e intención del mensaje. Los epitafios son una fuente relevante para conocer el pensamiento griego: lo allí escrito debía tener sentido para la sociedad en su conjunto.

Palabras Clave: epitafios, Grecia clásica, deixis, comunicación, acto de habla

\begin{abstract}
This text will analyze the way in which deictic elements, particularly those for place (here) and time (now) play a role to make some funerary epitaphs from the classical era in the Attic region be considered a representation of "acts of speech", that is, each time they are read, communication actions in a given context happen once again; these actions contain three elements: sender, receiver and message intention. Epitaphs are an important source to get to know Greek thought, because what was written there had to make sense for the society as a whole, as will be shown below.
\end{abstract}

Keywords: epitaphs, Classic Greece, deixis, communication, speech act

Recepción 05-06-19 / Aceptación 02-10-19 
* Doctora en Letras por la UNAm (2014), en donde también obtuvo los títulos de Licenciada (2003) y Maestra (2008) en Letras Clásicas. Ha impartido materias del área de lengua griega en el Colegio de Letras Clásicas de la unam. Desde el año 2006 trabaja como profesora-investigadora de tiempo completo en la Universidad Autónoma de la Ciudad de México (UACM). Ha participado en diversos congresos nacionales e internacionales, con ponencias relativas a la cultura griega arcaica y clásica, con temas específicos como los epigramas funerarios, el orfismo y las manifestaciones de las creencias relativas a la muerte en el mundo griego. Actualmente coordina y colabora en el libro titulado Tensiones y porosidades. Fronteras que resignifican la vida, una coedición de la UACM y la editorial Ítaca. 
En Grecia, desde la época arcaica, fue importante dejar constancia física del lugar donde se enterraba a un difunto. A partir del siglo viI, con la introducción y extensión de la escritura, en la tumba — sobre una piedra algo más elevada o en el recipiente que contenía los restos— se escribía el nombre del difunto; esta redacción posteriormente se convirtió en epitafio o inscripción funeraria larga. Estas inscripciones sepulcrales constituyen el grupo más numeroso de todo el material epigráfico que nos ha heredado la Antigüedad. Si bien las inscripciones funerarias presentaron diversos tipos de metro, el género epigramático (dístico compuesto por un hexámetro y un pentámetro) fue el que tuvo mayor auge. ${ }^{1}$

1 En la Antigüedad, estos testimonios se compilaron en la Antología Griega, formada por la Antología Palatina y la de Planudes. En tiempos recientes se han realizado varias antologías, algunas con traducciones, por ejemplo la de Georgius Kaibel, Epigrammata Graeca ex Lapidibus Collecta (Berlín: G. Reimer, 1878); la de Johannes Geffcken, Griechische Epigramme (Heidelberg: Carl Winters Universitätsbuchhandlung, 1916); la de Paul Friedläender, Epigrammata: Greek Inscriptions in Verse from the Beginnings to the Persian Wars (Berkeley-Los Angeles: University of California Press, 1948); la de Peter Jay, The Greek Anthology and other Ancient Greek Epigrams: A Selection in Modern Verse Translation (Londres: Penguin Books, 1973); la de Peter Allan Hansen en dos volúmenes, Carmina Epigraphica Graeca (Berlín: De Gruyter, 1983/1989); o la de Gordon L. Fain, Ancient Greek Epigrams (Berkeley-Los Angeles: University of California Press, 2010). Para el estudio específico de éstos, se cuenta con la edición de Werner Peek, Greek Verse Inscriptions. Epigrams on Funerary Stelae and Monuments (Chicago: Ares Publishers, 1988). Además, hay algunos estudios con temas relacionados, como el de Richmond A. Lattimore, Themes in Greek and Roman Epitaphs (Urbana-Champaign: The University of Illinois Press, 1942); el de Luigi Spina, La forma breve del dolore: ricerche sugli epigrammi funerari greci (Amsterdam: Adolf M. Hakkert, 2000); el de Katharine Derderian, Leaving Words to Remember. Greek Mourning and the Advent of Literacy (Leiden, Boston, Colonia: Brill, 2001); el de Julia Lougovaya-Ast, An Historical Study of Athenian Verse Epitaphs from the Sixth Through the Fourth Centuries BC (Tesis de Ph. D, University of Toronto, 2004); el de Jon Steffen Bruss, Hidden Presences: Monuments, Gravesites, and Corpses in Greek Funerary Epigram (Lovaina, París, Dudley, MA: Peeters, 2005); el de Christos Tsagalis, Inscribing Sorrow: Fourth-Century Attic Funerary Epigrams (Vol. 1, Berlín, Nueva York: Walter de Gruyter, 2008); o el de Joseph Day, Archaic Greek Epigram and Dedication: Representation and Reperformance (Cambridge: Cambridge University Press, 2010). En español, María Luisa del Barrio Vega, Epigramas funerarios griegos (Madrid: Gredos, 1992), hace una traducción de una selección y presenta un estudio introductorio. 
De estos epigramas grabados en las estelas funerarias se obtuvo la información presentada en este trabajo, ${ }^{2}$ las traducciones del griego son de la autora, a menos que se indique otra cosa. Se utilizaron estos epigramas porque si bien no son fuente de información para conductas individuales (dado que muchas veces son valores idealizados, por ejemplo, la prudencia o la piedad de una persona), sí funcionan para creencias generales; es decir, muestran las acciones o actitudes "bien vistas" por la sociedad de ese momento.

Específicamente se utilizarán los de la región ática de la época clásica, compilados por Hansen en Carmina Epigraphica Graeca, debido a que es la antología más completa y mejor editada. Se anotará entre paréntesis el número asignado por él a cada epigrama. De 105 epigramas funerarios áticos de los siglos viII a v (CEG 1) y 160 del siglo IV (CEG 2) recopilados por Hansen, se seleccionaron los pertenecientes a la época clásica (desde inicios del siglo v hasta la muerte de Alejandro Magno en 323 a. C.), se dejaron de lado aquellos que estaban muy dañados debido a que los datos que aportaban no eran suficientes para llegar a una conclusión. Resultaron 170 epigramas funerarios en total.

Una de las funciones de estos epigramas funerarios en la época clásica era que quien pasara frente a ellos los leyera (aunque tal vez poca gente podía leerlos en realidad). ${ }^{3}$ Propongo que cada vez que alguien leía el

Aunque ciertamente sería provechoso utilizar también fuentes iconográficas para este estudio, la extensión resultante rebasaría los límites establecidos para una investigación como la presente.

Acerca del nivel de alfabetización, de su importancia y sus consecuencias en Grecia, ha habido diferentes enfoques: Eric Havelock afirmó que, gracias a la instrucción alfabética, Grecia llegó a ser la gran cultura que fue. Eric A. Havelock, Preface to Plato (Cambridge: Harvard University Press, 1963). Por su parte, William Harris enfatizó que pocas personas, fuera de la élite educada, eran alfabetizadas, a cualquier nivel, y que nunca se dio una alfabetización masiva. William V. Harris, Ancient Literacy (Cambridge: Harvard University Press, 1989). Alfred Burns señaló que, desde finales del siglo vi, la gran mayoría de los ciudadanos atenienses era alfabeta. "Athenian Literacy in the Fifth Century B. C.”, Journal of the History of Ideas, vol. 42, núm. 3 (jul.-sep. 1981): 371-387. Posteriormente, William A. Johnson y Holt N. Parker explican que, en Atenas, la línea en la cual 
epitafio, se volvía a presentar (se representaba) un "acto de habla". ${ }^{4} \mathrm{El}$ concepto acto de habla fue propuesto por John Langshaw Austin a lo largo de varias conferencias publicadas en 1962 con el título Cómo hacer cosas con palabras. Dicho concepto se inserta en el ámbito de la pragmática (el lenguaje en la comunicación), ${ }^{5}$ y refiere al acto que se lleva a cabo cuando un hablante produce un enunciado con el que obtiene una reacción a partir de su intención (orden, petición, aserción, promesa, entre otras) en el oyente. Por ejemplo, al emitir un enunciado como: "te prometo que lo entregaré", estamos diciendo algo, prometiendo una acción (intención) y provocando un efecto (convencer al interlocutor de la promesa). Siguiendo a Austin, propongo que estos epigramas constituyen enunciados performativos (distintos a los constatativos, en los cuales sólo se hacen aseveraciones), ya que en su producción el hablante o autor lleva a cabo un acto de hacer más que de decir. ${ }^{6}$

Este acto de habla resulta fundamental en la sociedad griega debido al papel tan importante que tenía la imagen propia (actitudes y acciones) frente a los demás. Así, se puede asegurar que otro de los fines de estos epigramas era que toda la sociedad tuviera en mente las cualidades plasmadas, referidas a cualquier difunto.

Para el análisis de los epigramas aquí presentados, partimos de la idea de la presencia de un hablante, un oyente y una intención en el mensaje.

alguien estaba en desventaja seria por sus pobres habilidades de escritura era muy baja, pero eso no significa que hubiera un nivel educativo y político igual al de la élite. William A. Johnson, y Holt N. Parker (eds.). Ancient Literacies. The Culture of Reading in Greece and Rome (Oxford: Oxford University Press, 2009).

4 Evelia Arteaga, “¿Cómo 'habla’ el epigrama funerario ático? Una relación entre vivos y muertos”, Nova Tellvs, $37 / 2$ (julio-diciembre 2019), 49-65.

5 M. Victoria Escandell Vidal, Introducción a la pragmática (Madrid: Universidad Nacional de Educación a Distancia, 1993).

6 John Lyons, Semántica lingüistica. Una introducción (Barcelona, Buenos Aires, México: Paidós, 1997), 261. 
Se analizará la forma en que estos mensajes se actualizan, volviéndose a presentar (a representar) cada vez que alguien los leía (quizá en voz alta). Por ello, era de suma importancia la referencia al contexto de dicho acto, como explica Escandell: "comprender una frase no consiste simplemente en recuperar significados, sino también en identificar referentes. No basta con entender las palabras; hay que saber a qué objetos, hechos o situaciones se refieren"?

La referencia al contexto se lleva a cabo, entre otros recursos, a través del uso de elementos deícticos. El análisis de los epitafios en este texto se hará con base en los elementos deícticos de espacio y tiempo: "aquî" y "ahora", pero también se hablará de otros que refieren al contexto, para reforzar la tesis de la constante presentación (representación) de los actos de habla performativos.

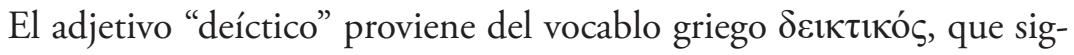
nifica "capaz de mostrar"; esto es, muestra la referencia al contexto (necesaria para la comunicación). Isabel Martín afirma que la deixis es el ámbito por excelencia en que el lenguaje y la realidad confluyen: "gracias a este mecanismo las lenguas establecen el punto de referencia necesario para la orientación del discurso en cada una de las situaciones comunicativas posibles". ${ }^{8}$ El hecho de que los elementos del acto de habla (emisor y receptor) estén disociados temporal y espacialmente logra esta representación constante del mismo; el acto de habla en los epitafios se completa con la acción de quien lo lee posteriormente (tal vez años después) a su realización.

La mayoría de los epitafios (no sólo griegos) contiene un elemento deíctico, debido a que literalmente el cuerpo del difunto está en ese lugar determinado, por ejemplo: "aquí yace" o "aquí se encuentra”. La parti-

Escandell, Introducción, 24.

Isabel Martín López, "Deixis frente a anáfora en griego antiguo”, Minerva. Revista de filología clásica 8 (1994), 11. 
cularidad de esta investigación reside en que estos deícticos se analizarán teniendo en cuenta la mencionada representación del acto de habla; es decir, su actualización constante. El interés por el tema no es nuevo; Díaz de Cerio, en su análisis de la estructura discursiva de algunos epigramas, explica que la constante aplicación de formas deícticas al monumento funerario griego, al difunto o a la propia situación, manifiesta la "actualización" sobre la cual los compositores de los epigramas poseían conciencia desde época temprana. ${ }^{9}$

Revisaremos ocho epigramas; cuatro tienen como eje el tiempo y cuatro, el lugar. He aquí el primero (89):

I.

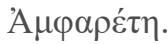

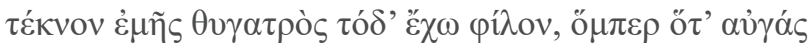

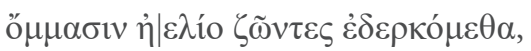

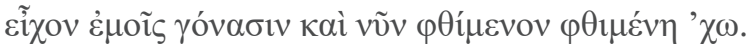

Anfárete.

Tengo a este querido hijo de mi hija (cuando estábamos

vivos veíamos con los ojos los rayos del sol),

lo tenía en mis rodillas y ahora, muertos él y yo, lo sigo teniendo. ${ }^{10}$

En este epigrama habla la mujer difunta en primera persona, se vuelve emisora del acto de habla. Ella, en el primer verso, utiliza un deíctico demostrativo "este", $\tau$ ó $\delta \varepsilon$, que determina al niño, $\tau \varepsilon ́ \kappa v o v$, que tuvo en su regazo cuando vivían y lo sigue teniendo, incluso muertos ambos. Utiliza este deíctico para contextualizar al emisor, para relacionarse con éste, como si todo estuviera ahí presente.

9 Mercedes Díaz de Cerio, "Estructura discursiva en el epigrama funerario: la evolución de un género”, Habis 30 (1999), 199.

10 Traduzco el verbo $\varepsilon \chi \omega$ de la cuarta línea usando una perífrasis con el objetivo de mantener el sentido de duración que el tiempo presente del modo indicativo tiene en la lengua griega. 
El hecho de haber tenido al nieto en su regazo en la vida y en la muerte se reafirma con otro deíctico: el adverbio "ahora”, vṽv, componente que recuerda al lector que en este momento ambos, abuela y nieto, están muertos. Ángel López asevera que la deixis no sólo es la forma en que quedan reflejadas lingüísticamente las relaciones espaciales entre entidades, sino que constituyen, al mismo tiempo, un procedimiento con el cual las coordenadas espaciales se crean o transforman. ${ }^{11}$

El que se repita dos veces el verbo en presente "tengo", है $\chi \omega$ (en la segunda línea y al final de la cuarta aunque sin la vocal inicial), acentúa que la acción sigue sucediendo, una presentación que se actualiza constantemente a través de la lectura del epitafio. Así, el lector da vida a la mujer difunta y a su situación. Es también importante que el verbo aparezca en pretérito imperfecto, "tenía", عĩ ¿ov, ya que en griego ambos tiempos son considerados formas con un matiz o aspecto durativo; esto refuerza la intención de que eso continúe, que la abuela y el nieto estén juntos siempre, que se presenten siempre; lo cual podría ser un alivio para los padres del pequeño quienes, seguramente, realizaron el monumento funerario.

Fred Miller propone que este epigrama es el primero que pretende describir la condición del muerto en el Hades. Implica la idea de que la abuela muerta y el nieto mantienen en el inframundo la misma relación que cuando estaban vivos. ${ }^{12}$ Dado que en el epigrama no hay más elementos que indiquen una creencia en la existencia de las almas post mortem, se puede pensar que lo ahí escrito sólo refleja que la abuela y el nieto habían sido enterrados juntos; pero también sería la expresión del deseo de los padres del niño de que éste disfrute de una cierta existencia aun después de muerto.

Ángel López y otros, Lingüistica general y aplicada (Valencia: Universidad de València, 1999), 249. Fred D. Miller Jr., "Philosophical Themes in Early Greek Grave Inscriptions", XI Congresso Internazionale di Epigrafia Greca e Latina, Roma, 18-24 septiembre 1997, Atti I (Roma: Edizioni Quazar, 1999), 194. 
El segundo epitafio también está escrito en primera persona, pero plural (544):

II.

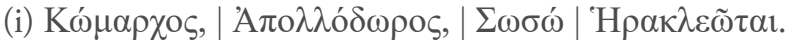

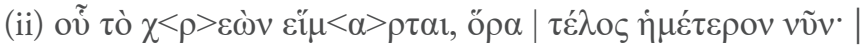

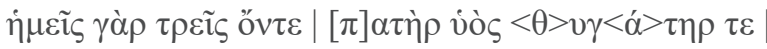

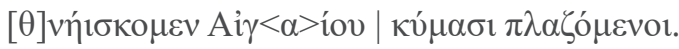

(i) Comarco, Apolodoro, Soso Heracleotas.

(ii) Mira nuestro fin ahora, cuyo destino fue ordenado;

pues nosotros éramos tres, padre, hijo e hija

y morimos extraviados en las olas del Egeo.

Este epigrama estaba inscrito en un cenotafio (una tumba sin los cuerpos de los difuntos, ya que éstos se perdieron en el mar), por lo cual no fue posible utilizar un elemento deíctico de lugar; por este motivo resulta más importante el uso del adverbio de tiempo, võv, como elemento que indica la situación de esas tres personas al momento de leer la inscripción, en contraposición con lo que fueron en vida.

La primera línea sólo menciona sus nombres. La segunda, además de presentar al final el adverbio de tiempo "ahora", võv, tiene, a la mitad, un imperativo "mira", ő $\rho \alpha$, en segunda persona del singular (del verbo "ver" ópó( ), esto refleja una llamada al caminante que llegara a pasar por ahí y viera la tumba.

En cuanto al caminante, su figura entró en Ática en los epigramas del siglo vi tan completamente formada que es factible creer que existiera desde antes (al menos oralmente). Del Barrio Vega explica los pasos en que está involucrado el caminante en este siglo vi: primero se llama

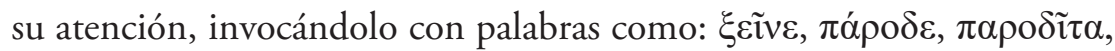

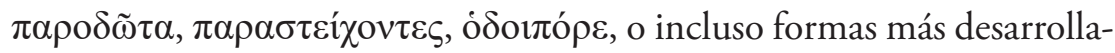
das como la siguiente, del mismo siglo: 


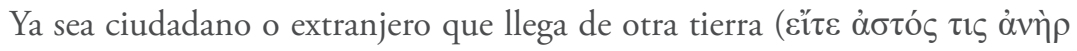

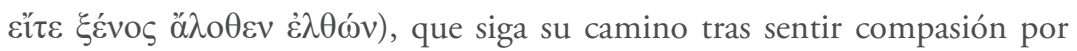
Tético, un valiente que en combate murió y perdió la vigorosa juventud. Lamentaos por ello y volved en buena hora a vuestros asuntos. ${ }^{13}$

Se le hace al viandante la petición de que se detenga y sienta piedad por el muerto. A veces, se le pide también que haga alguna ofrenda o libación sobre el sepulcro. El epigrama acaba frecuentemente con la fórmula habitual de saludo ( $\chi \alpha i ̃ \rho \varepsilon, ~ \chi \alpha i ́ \rho \varepsilon \tau \varepsilon)$ al caminante. A cambio de su compasión y su saludo se le desea que acabe felizmente su viaje, así como el resto de su vida. ${ }^{14}$

En ocasiones aparece el encargo de transmitir un mensaje: el difunto o el monumento sepulcral piden al caminante que comunique la noticia de su muerte. Por lo general, la fórmula es: "si vas a...", más la ciudad del difunto, "diles a...", más el nombre de los padres de éste. Un ejemplo famoso es el epigrama de Leónidas y los espartanos caídos en las Termópilas referido por Heródoto: "Caminante, informa a los lacedemonios que aquí yacemos por haber obedecido sus mandatos"15

Debemos recordar que en Grecia la lectura se hacía en voz alta. De hecho, Jesper Svenbro, en su obra dedicada a la lectura en Grecia, afirma que la escritura griega era una máquina para producir sonidos. ${ }^{16}$ Así que no resultaba ajeno a los caminantes leer en voz alta el epitafio que veían. No obstante, dado que la evidencia literaria de la recepción de los

13 María Luisa del Barrio Vega, traductora, Epigramas funerarios griegos (Madrid: Gredos, 1992), fr. 62 .

14 María Luisa del Barrio Vega, "Función y elementos constitutivos de los epigramas funerarios griegos” Estudios Clásicos, tomo 31, núm. 95 (1989), 10.

15 Heródoto, Historia. Libro VII. Polimnia (trad. Carlos Schrader, Madrid: Gredos, 1985), VII. 228.9-10.

16 Véase Jesper Svenbro, Phrasikleia: Anthropologie de la lecture en Grèce ancienne (París: Editions La Découverte, 1988). 
epigramas en piedra es muy escasa, ${ }^{17}$ no sabemos con certeza si en realidad los caminantes los leían o no. Se cumpliera o no la intención de dirigirse a un caminante, el hecho es que algunos epigramas funerarios (cada vez menos en el siglo IV) concebían la posibilidad explícita de ello, completando así la múltiple presentación del acto de habla: su representación continua.

La figura del caminante en los epigramas funerarios analizados en el presente escrito tiene varias funciones: en primer lugar, para contextualizar el monumento funerario, es decir, para colocarlo en un tiempo y espacio determinados. Michael A. Tueller advierte que el imperativo empleado a veces para dirigirse a él sirve, en realidad, para marcar ese tiempo y espacio. ${ }^{18} \mathrm{El}$ mismo autor afirma que el caminante no es un concepto abstracto. Aunque el epigrama busca tener lectores nuevos, la tradición no sólo pretendía eso, sino que siempre buscó a alguien presente, en su tiempo y espacio actuales. ${ }^{19}$

En segundo lugar, el caminante es la figura faltante y necesaria para completar la representación del acto de habla; ahora sí se puede pensar en una comunicación completa, puesto que hay quien lo lea y quien lo repita, es decir, hay un receptor. Ruth Scodel afirma que una inscripción es un intento de controlar el discurso de un hablante ausente. En particular donde la lectura significa leer en voz alta, la persona que escribe en un medio permanente solicita a otros, a quienes no conoce y cuya visión de lo que él escribe es completamente imprevisible, que le den voz. ${ }^{20}$

17 Peter Bing, "The Un-Read Muse? Inscribed Epigram and Its Readers in Antiquity”, en M. A. Harder y otros (eds.), Hellenistic Epigrams (Lovaina: Peeters, 2002), 39-66; citado en Regina Höschele, "The Traveling Reader: Journeys through Ancient Epigram Books", Transactions of the American Philological Association 137, núm. 2 (otoño 2007), 333-369.

18 Michael A. Tueller, "The Passer-by in Archaic and Classical Epigram”, en Manuel Baumbach, Andrej Petrovic, Ivana Petrovic (eds.), Archaic and Classical Greek Epigram (Cambridge: Cambridge University Press, 2010), 44.

19 Tueller, "The Passer-by”, 59-60.

20 Ruth Scodel, "Inscription, Absence and Memory: Epic and Early Epitaph", Studi italiani di Filologia Classica, LXXXV annata, terza serie, volume X, fascicoli I-II (Florencia: Felice Le Monnier, 1992), 57. 
Finalmente, en tercer lugar, al completar el acto de habla, dicho caminante es el medio que tiene el epigrama funerario para actualizarse. Así, cada vez que alguien lo lee en voz alta, recuerda al difunto. "La participación de éste — dice Díaz de Cerio- facilita la forma de la constitución del epigrama en forma dramática”. ${ }^{21}$ Así, queda claro que hay un acto de habla completo: los emisores son los difuntos, ${ }^{22}$ el receptor es el caminante y la intención del mensaje es que se les recuerde, aunque sus cuerpos no hayan sido encontrados y enterrados ahí.

El tercer epitafio también se dirige a alguien en particular y por lo mismo está escrito en segunda persona, pero ya no es para un caminante, vivo, sino a la difunta ahí enterrada; no se sabe quién habla, pero le recuerda a ella las virtudes que tenía en vida y lo que deja a quienes le sobreviven (543):

III.

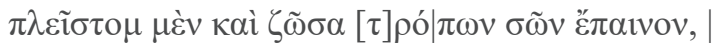

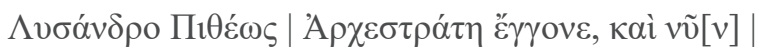

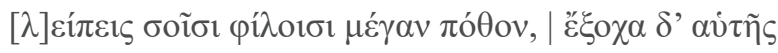

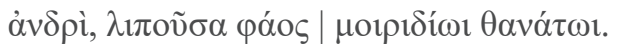

Viva, (recibías) muchísima alabanza por tus hábitos,

Arquéstrate, nieta de Lisandro, (del demo) de Pitio, y ahora

dejas a tus seres queridos gran nostalgia y en mayor medida a tu

esposo, tras abandonar la luz a causa de la muerte fatal.

El lector del epitafio se convierte en el emisor y la mujer difunta en el receptor; se contrapone lo que ella era antes de morir y lo que provoca en

$21 \quad$ Díaz de Cerio, "Estructura”, 201.

22 Dado que para un análisis de la fuente sólo tenemos lo que ahí se lee y este epigrama está escrito en primera persona, se puede deducir que el autor original del epigrama quería que se pensara que el emisor era el difunto mismo (para completar, así el acto de habla). 
la gente que deja en este mundo (con un verbo en presente $\lambda \varepsilon i ́ \pi \varepsilon 1 \varsigma$ ); esta comparación se logra precisamente con el elemento deíctico de tiempo "ahora", vข̃v.

La intención de este epitafio es recordar, a través de su lectura, que Arquéstrate fue una buena esposa en vida, por lo que su familia, en específico su esposo, la echará de menos. Hay que recordar que en la Atenas clásica la concepción ideal de la mujer era que tuviera hábitos o costumbres ( $\tau \rho o ́ \pi \omega v)$ adecuadas, en especial en el hogar, que se hablara bien de ella (mejor dicho, que no se hablara de ella). Al tener esas cualidades, la difunta no sólo fue digna de alabanzas por parte de la sociedad cuando vivía sino, incluso, muerta. Diana Burton explica que en las tumbas se evoca el papel de la mujer en la familia, implícitamente se les coloca en una ideología de la ciudad más amplia al enfatizar sus virtudes privadas como esenciales para la estabilidad del hogar, el mantenimiento de la ciudad y, además, la continuidad de la comunidad en un todo. ${ }^{23}$ Por su parte, Sourvinou-Inwood apunta que en varias ocasiones el vocabulario usado para mujeres es el mismo que para hombres; de ahí concluye que los epitafios reflejan el espectro más positivo de las representaciones colectivas acerca de las mujeres, la normativa sobre la buena mujer, en donde no se piensa que deban ser radicalmente diferentes a los hombres. ${ }^{24}$

Así, se observa que para los griegos la fama y la gloria se obtenían en esta vida, aquí y ahora, pero trascendían la muerte. La concepción de castigos y recompensas que pudieran presentarse en el más allá, aparecería, poco a poco, a través de los movimientos mistéricos. ${ }^{25}$ Por la

23 Diana Burton, "Public Memorials, Private Virtues: Women on Classical Athenian Grave Monuments”, Mortality, vol. 8, núm. 1 (2003), 20.

24 Christiane Sourvinou-Inwood, "Male and Female, Public and Private, Ancient and Modern”, en Pandora women in classical Greece, Ellen D. Reeder, ed. (Baltimore, Md., Princeton, N.J: Trustees of the Walters Art Gallery, Princeton University Press: 1995), 117-8.

25 Ver Alberto Bernabé y Ana Isabel Jiménez, Instrucciones para el más allá. Las laminillas órficas de oro (Madrid: Ediciones Clásicas, 2001); Alberto Bernabé y Francesc Casadesús, coords. Orfeo y la tradición órfica. Un reencuentro I y II (Madrid: Akal, 2008). 
importancia del "aquí y ahora", los deícticos en los epitafios, pensados y compuestos como un acto de habla, tienen tanto sentido: las cualidades de alguien, en este caso de una mujer, deben presentarse una y otra vez a todo quien lo lea.

En este epigrama, la situación comunicativa la crea el lector frente a la tumba de la mujer difunta quien se vuelve la receptora, para ello resulta adecuado pensarla ahí presente. Esta comunicación (entre el lector y la mujer difunta) se ve reforzada por el posesivo "tus", бoĩ que también funciona como un deíctico; es decir, el lector le habla a ella directamente.

El eje temporal es importante por lo anterior: la fama era y será eterna, entonces el deíctico vṽv es imprescindible, así como el verbo en presente "dejas", $\lambda \varepsilon i ́ \pi \varepsilon ı$. Recordemos que en griego, el elemento aspectual del presente indica que la acción continúa, es durativa; por lo que si algo, como la fama, perdura por mucho tiempo, hay que expresarlo en tiempo presente.

Por otro lado, este epitafio muestra una concepción ineludible de la vida y la muerte, ya que como se aprecia, el sustantivo muerte, $\theta \alpha v \alpha ́$ $\tau \omega 1$, tiene como modificador "fatal", $\mu$ oipı $\delta i ́ \omega t$, procedente de la palabra $\mu$ oĩpa (de donde viene la concepción de las Moiras: las personificaciones del destino) que recuerda, literalmente, la parte que le corresponde a cada quien, de la cual no se sale ni escapa: el destino. Al ser humano no le queda más remedio que vivir lo que le toca y esperar la muerte inevitable, esto se hacía presente al leer este epitafio.

El cuarto y último epigrama con eje temporal, es el siguiente (571):

IV.

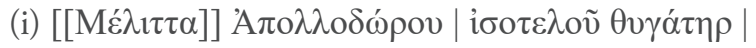

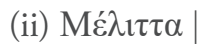

(iii) $\tau i ́ \tau \theta \eta$.

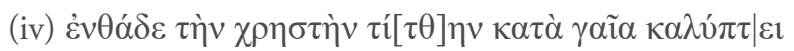




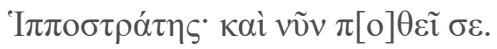

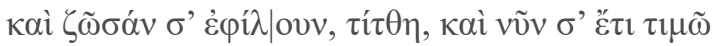

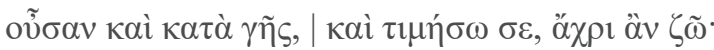

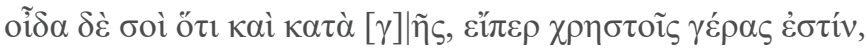

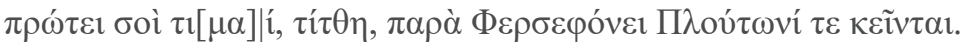

(i) Melita (hija) de Apolodoro, que contribuía como un ciudadano.

(ii) Melita.

(iii) Nodriza.

(iv) Aquí debajo, la tierra cubre a la buena nodriza

de Hipóstrate, (quien) ahora suspira por ti.

Te quería estando viva, nodriza, y ahora todavía te honro

estando tú bajo tierra, y te honraré mientras viva.

Sé que, si es verdad que bajo tierra hay una distinción honorífica para los buenos,

en primer lugar, los honores están dispuestos para ti, nodriza, en la morada de Perséfone y Plutón.

Este epitafio está escrito en primera persona pero, al igual que el anterior, está dirigido a una difunta. Señala que Melita era hija de un isoteles, categoría de meteco (vocablo cuya etimología es el prefijo $\mu \varepsilon \tau \alpha ́$ y el

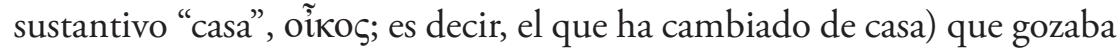
en Atenas de un estatus privilegiado ya que, aunque no era ciudadano, sí podía adquirir propiedades, pues pagaba "igualdad de impuestos" ${ }^{26}$ La actividad de nodriza, a la cual se dedicaban numerosas esclavas, atraía también a mujeres libres. Si eran competentes, dice Lougovaya-

26 Ver Torben Vestergaard, "Bárbaros y otros extranjeros en el Atenas clásica: el testimonio de los epitafios”, Patricia Villaseñor (trad.), Nova Tellus, 21-1 (2004), 56-57; Anna Ginestí Rosell, "Próxenos, métoikos, isotelés. La integración de extranjeros en Atenas", Faventia Supplementa 2. Contacto de poblaciones y extranjería en el mundo griego antiguo (Barcelona: Universitat Autònoma de Barcelona, 2013), 297; Peter Marhall Fraser, Greek Ethnic Terminology (Oxford: Oxford University Press, 2009), 117. 
Ast, gracias a esta actividad podían encontrar un hogar estable y un reconocimiento social no despreciable. ${ }^{27}$

Quien recita el epigrama dirigido a Melita, explica Anna Ginestí, es la niña cuidada por ella, Hipóstrate, "por ello se intenta imitar en él el lenguaje infantil con estructuras sintácticas simples y muchas repeticiones". ${ }^{28}$ Una de estas palabras duplicadas es el adverbio de tiempo "ahora", vข̃v, con el cual la niña hace una especie de continuo: afirma que la quería antes y también ahora, y que a su muerte, la seguirá honrando; además, dice que la nodriza podrá obtener beneficios en el más allá dadas sus cualidades en vida.

La idea de que el alma tuviera un destino individual después de la muerte del cuerpo proviene de los llamados misterios griegos, especialmente del orfismo. Si bien en los poemas de Homero ya se hablaba de castigos y recompensas, ${ }^{29}$ éstos eran para héroes o gente fuera de lo común, como quienes combatieron en Troya, esto hace pensar que una persona no esperaba un destino mejor (o peor) que el de la mayoría.

Los estudiosos del orfismo han llegado a conclusiones al respecto no sólo gracias a las referencias de autores griegos (como Platón), sino también por diversos documentos específicos, como el papiro de Derveni o las laminillas de oro, encontradas en diversas tumbas, al lado de los

27 Julia Lougovaya-Ast, "An Historical Study of Athenian Verse Epitaphs from the Sixth through the Fourth Centuries BC” (tesis de Ph.D., University of Toronto, 2004), 196.

28 Anna Ginestí Rosell, "Mujeres extranjeras en los epitafios atenienses”, Faventia Supplementa 2, Contacto de poblaciones y extranjería en el mundo griego antiguo (Barcelona: Universitat Autònoma de Barcelona, 2013), 333. Asimismo, ver Anna Ginestí Rosell, "Las inscripciones funerarias como fuente de información sobre el estatus socio-jurídico de las mujeres extranjeras en Atenas", en Actas del XII Congreso Español de Estudios Clásicos I (Madrid: Sociedad Española de Estudios Clásicos, 2009), 769.

29 Había penitentes: Tántalo (Homero, Odisea, XI. 582-592) y Sísifo (Homero, Odisea, XI. 593-600), y en el polo opuesto está la mención del "Campo Elisio" (Homero, Odisea, IV. 560-569), como destino de Menelao. 
esqueletos, datadas entre el 400 y el 200 a. C. ${ }^{30}$ Dichas laminillas contienen instrucciones precisas de lo que el difunto debía hacer al llegar al más allá, al parecer era necesario que el difunto recordara que había sido iniciado en el orfismo. En algunas de estas laminillas se especifica que el alma del difunto debe dirigirse a Perséfone, ${ }^{31}$ ya que ella decidirá el destino de ésta: "Ahora vengo como suplicante junto a la casta Perséfone / por ver si me envía a la morada de los límpidos". ${ }^{32}$

Las nociones de un destino específico según el comportamiento en vida aparecen en citas relacionadas con Orfeo. A Platón no parece agradarle la existencia de un banquete eterno después de la muerte, como lo menciona en República al referirse a lo que Museo y su hijo (en varios testimonios, Orfeo es hijo de Museo) proponen:

Museo y su hijo, por su parte, conceden a los justos, de parte de los dioses, bienes más resplandecientes que los de Homero y Hesíodo. Según lo que se narra, en efecto, los llevan al Hades, coronadas sus cabezas, les preparan un banquete de santos y les hacen pasar todo el tiempo embriagados, con el pensamiento de que la retribución más bella de la virtud es una borrachera eterna. $^{33}$

30 Ver Bernabé y Jiménez. Instrucciones para el más allá.

31 Perséfone tiene un lugar especial en el orfismo (y en estos epigramas funerarios) porque es la soberana del Hades y, además, en la cosmogonía órfica, es madre de Dioniso, dios fundamental en la existencia de los seres humanos, creados de las cenizas de los Titanes fulminados por Zeus en castigo por haber devorado a Dioniso. Como explica Bernabé, este dios y Perséfone tienen relación con la salvación humana: Dioniso porque, según el mito de los Titanes, una parte de él sobrevive en los seres humanos, por ello se identifican con él; y Perséfone, como soberana del Hades, quien controla el acceso al prado de los bienaventurados, ante ella llegan los iniciados como suplicantes y dirigen sus declaraciones de pureza y liberación. Ver Alberto Bernabé, “The Gods in Later Orphism”, en Jan N. Bremmer y Andrew Erskine, eds. The Gods of Ancient Greece (Edimburgo: Edinburgh University Press, 2010), 437.

32 Bernabé y Jiménez, Instrucciones, laminilla 10a.

33 Platón. República. En Diálogos IV (traducción de Conrado Eggers Lan. Madrid: Gredos, 1986), $363 \mathrm{c}-\mathrm{d}$. 
No es posible afirmar que la niña de este epitafio fuera órfica, más bien estas ideas debieron de estar presentes en la mente de la sociedad, de lo contrario, escribirlas en el epigrama no hubiera tenido ningún sentido. Además, si se creía que la nodriza seguía teniendo una existencia post mortem se hace más claro el sentido de la representación de un acto de habla entre la niña y su nodriza.

En estos cuatro epigramas funerarios que contienen, entre otros elementos deícticos, el adverbio de tiempo ahora, võv, la intención del mensaje es recordar por siempre a los difuntos por sus cualidades o acciones en vida, a través de presentar una y otra vez el acto de habla. Por otro lado, dependiendo las creencias acerca del más allá de los realizadores de los epitafios, se pensaba que el difunto podría tener o no una existencia post mortem. Dicho elemento deíctico hace una clara distinción entre vida y muerte (como en los epigramas II y III) o refleja un continuo entre ambas esferas (como en I y IV).

Pasemos al otro eje de análisis, el locativo. El deíctico de lugar, aquí, resulta fundamental en la mayoría de los epitafios, no sólo los griegos, debido a que el cuerpo del difunto está en ese preciso lugar, en la tumba, como el siguiente epigrama griego ático de época clásica (85):

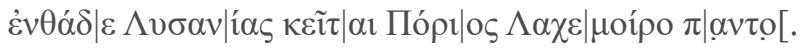

Aquí yace Lisanias Porio hijo de Laquemero...

En los siguientes cuatro ejemplos se analizará el uso del elemento deíctico de lugar como componente en la representación de un acto de habla. En el primero, el tú receptor cambia dentro del mismo epitafio: primero es la mujer difunta y después ella misma se dirige a su esposo (530):

$\mathrm{V}$.

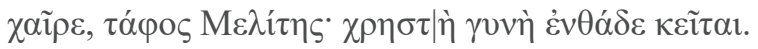

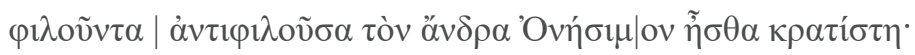




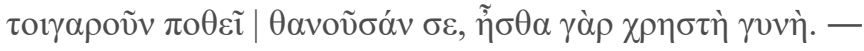

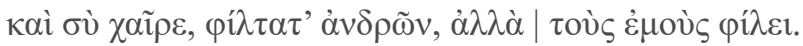
¡Salud!, sepulcro de Melita; una buena mujer yace aquí.

Amando de forma correspondida a tu esposo Onésimo, eras la mejor; por ello él te echa de menos a ti, muerta, pues eras una buena mujer. “También tú, salud, el más amado de los hombres, pero ama a los míos”.

Este epitafio resulta interesante debido precisamente al cambio de persona narrativa. Empieza el emisor, quien lee el epitafio, dirigiéndose a la mujer difunta, le recuerda que está allí, દ̇v $\theta \alpha ́ \delta \varepsilon$, enterrada y, más importante, que fue una buena mujer, amaba y era amada por su esposo. En estos primeros tres versos son relevantes dos deícticos: el de lugar, aquí, $\dot{\varepsilon} v \theta \alpha ́ \delta \varepsilon$, y el pronombre personal "te", $\sigma \varepsilon$, usado para referirle a la difunta que su esposo la echa de menos. Con estos dos elementos el emisor representa el acto de habla al interpelar a la mujer difunta.

En el cuarto y último verso es la mujer difunta quien se dirige a su esposo, representado en ese acto de habla por el lector; ella, además de recordarle que lo ama, le pide que ame a los "suyos", es decir, a sus

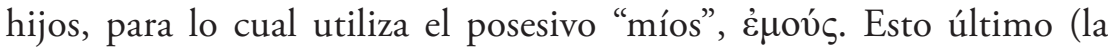
petición al esposo) pudiera ser sólo una muestra de que ella había tenido hijos, lo cual era parte de sus obligaciones como mujer en Atenas (con mayor medida si era esposa de un ciudadano, ya que debía procrear hijos que también lo fueran); a partir de eso (y de tener hábitos y cualidades adecuadas en el hogar) ella se ganaba el reconocimiento social. De esta manera, la fama del aquí y ahora se podía extender más allá de la muerte, a la eternidad; a través de la lectura del epitafio y de la representación constante del acto de habla. La intención de este epigrama funerario es recordar no sólo a la difunta por haber cumplido lo que la sociedad esperaba de ella, sino también las cualidades que toda mujer (idealmente) debía atender en esa sociedad: ser buena con su esposo y tener hijos. 
El segundo epitafio con eje locativo es el siguiente (11):

VI.

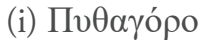

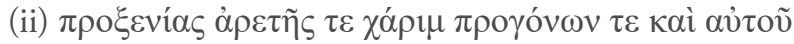

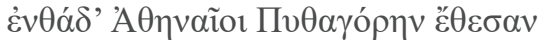

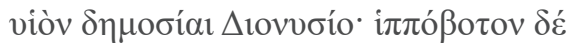

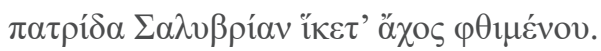

(i) De Pitágoras.

(ii) A causa de sus funciones como próxeno y a causa de su excelencia, tanto la suya como la de sus antepasados,

aquí los atenienses enterraron en un sepelio oficial a Pitágoras,

hijo de Dionisio; a su patria abundante en pastos para los caballos,

Selimbria, ha llegado la pena de su muerte.

En este epigrama se resalta lo que fue en vida no sólo el difunto, también sus antepasados; a partir de esto, él obtiene un sepelio oficial, organizado y pagado por Atenas. Un próxeno era un extranjero residente en una ciudad, encargado de gestionar los asuntos de sus compatriotas, recibir a sus embajadores y apoyar sus negociaciones, era importante para el funcionamiento de Atenas.

Anna Ginestí explica que la ciudad de Selimbria fue miembro de la liga ático-délica probablemente desde sus inicios, en el año $477 \mathrm{a}$. C. La actividad de Pitágoras como próxeno de los atenienses parece coincidir con ese periodo de gran actividad política "internacional” de Atenas, por lo cual es verosímil creer que él propiciara la inclusión de su ciudad en la liga ático-délica. Añade Ginestí que es uno de los primeros proxenoi atenienses de los que se conserva noticia epigráfica, aunque la referencia a la proxenía y excelencia de sus antepasados conduce a pensar que, por lo menos el padre de Pitágoras, Dionisio, debió ser también próxenos de los atenienses alrededor de la época de las guerras médicas. Dispensar un 
funeral con honores públicos era uno de los deberes de la ciudad para con sus proxenoi. ${ }^{34}$

Este epitafio está escrito en tercera persona: el que lo lee se convierte en emisor y receptor al mismo tiempo; de hecho, considerando lo ahí escrito, se puede pensar que la sociedad entera es tanto la emisora como la receptora, es ella la que reconoce y, al mismo tiempo, a quien se le recuerda lo que alguien puede obtener si es útil en vida. La intención es representar, cada vez que se lee, el recuerdo positivo del ahí enterrado (por ello se inscribe aquello que lo hizo sobresalir, su excelencia, $\grave{\alpha} \rho \varepsilon \tau \tilde{\eta} \varsigma$ ) y, al mismo tiempo, la importancia de contribuir al bienestar de la polis ateniense.

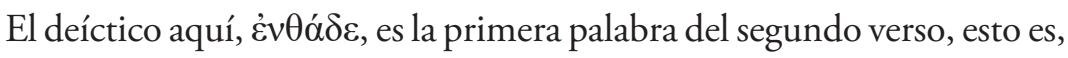
del pentámetro; y la patria, $\pi \alpha \tau \rho i ́ \delta \alpha$, del difunto es la primera palabra del segundo pentámetro (del cuarto verso). Así, tenemos una contraposición entre el lugar donde está enterrado, Atenas, y su patria, Selimbria. Cada una de estas ciudades ocupa dos versos del epigrama: en los primeros dos se habla de lo que el difunto logró y, en los segundos, lo que dejó. Se aprecia con claridad la importancia del eje locativo en este epigrama funerario. Dado que aquí importa lo que el difunto hizo por Atenas, lo que la ciudad recibió de su parte, no hay dolor ni tristeza por su muerte, no hay un antes y un ahora (eje temporal); sólo dos lugares distintos.

En el siguiente epigrama funerario se habla de la morada de Perséfone como lugar a donde llegan las almas de los muertos (510):

VII.

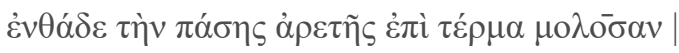

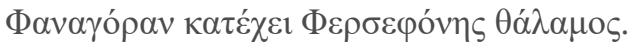

$34 \quad$ Anna Ginestí Rosell, "Presencia de extranjeros en Atenas a partir de las inscripciones funerarias: el epigrama en honor de Pitágoras de Selimbria (IG I 1154)”, en Actas del XI Congreso de la Sociedad española de estudios clásicos II (Madrid: Sociedad Española de Estudios Clásicos, 2005), 308. 
Aquí, habiendo llegado al extremo de toda excelencia, a Fanágoras retiene la morada de Perséfone.

Este epitafio, escrito en tercera persona, empieza con el deíctico de lugar aquí, $\dot{\varepsilon} v \theta \alpha ́ \delta \varepsilon$, en el primer verso se remarca que el difunto cumplió con

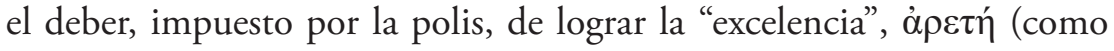
en el anterior). En el segundo se habla del lugar donde se piensa que está

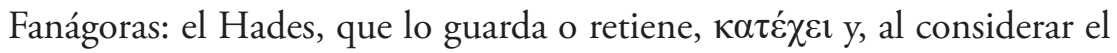
aspecto durativo del verbo en presente, lo seguirá haciendo por mucho tiempo más. A través del elemento deíctico $̇ \dot{v} \theta \alpha ́ \delta \varepsilon$ se igualan el lugar físico donde se encuentra el cuerpo sin vida de Fanágoras y el Hades.

Ya que el primer verso empieza con "aquî", el segundo con el nombre

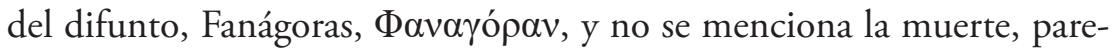
ciera que él sigue vivo pero en otro lado, no hay tristeza ni lamentos; en ese lugar específico, en la tumba, está sólo el recuerdo de lo que hizo en vida. En este epitafio, el difunto no juega el papel de receptor, incluso no hay una segunda persona; es sólo el lector, emisor, quien lo recuerda una y otra vez. Se podría suponer que es este lector, emisor y receptor, quien recibe el mensaje: teniendo excelencia, la presencia (aunque no física) será eterna, la cual se representará una y otra vez a través de la lectura del epitafio.

El hecho de que el verbo para referirse al destino del alma del difunto esté en presente, implicaría una concepción acerca del más allá en donde los difuntos continúan con las características que tenían en vida y, tal vez, pagan sus faltas o reciben recompensas, como se analizó en el epigrama Iv (571 de Hansen). Esto se refuerza por la presencia de Perséfone, sin embargo, no hay nada más que lo asegure, por lo que quizá era sólo un tópico literario común al momento de la creación del epitafio.

En el último epitafio analizado se mezclan la tercera y la primera persona (492): 
VIII.

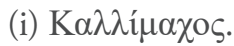

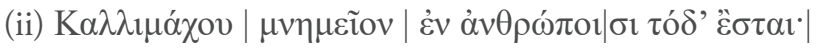

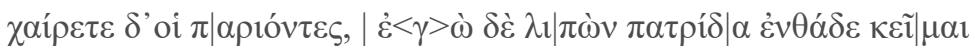

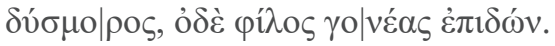

(i) Calímaco.

(ii) Éste será el monumento de Calímaco entre los hombres.

“'Saludos, caminantes! Yo, después de abandonar mi patria, yazgo aquí, desgraciado, sin haber visto a mis queridos padres."

El primer verso es la presentación del difunto, la cual utiliza el pronom-

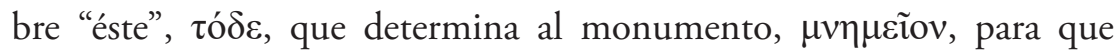
quien lea el epigrama tenga conciencia clara del objeto del cual se está hablando.

Después de contextualizar al lector, se cambia de persona narrativa, ahora es el difunto el que se dirige a los caminantes: se utiliza, además de

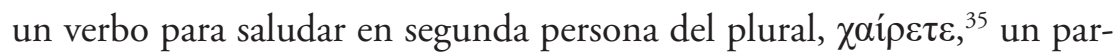
ticipio, $\pi \alpha \rho$ óv $\tau \varepsilon \zeta$, sustantivado con el artículo "los", oi. Ese participio viene del verbo $\pi \alpha ́ \rho \varepsilon \uparrow \mu 1$, que significa "ir a un lado, ir cerca”. Esta forma de llamar a un lector remite, de manera más literal, a los caminantes, a quienes pasan al lado del monumento funerario y se detienen a leer el epitafio. Así se completa la representación continua del acto de habla, por lo que, esos lectores podemos ser también nosotros en este momento.

El difunto cuenta a los caminantes que él no es de ese lugar en donde está enterrado, al usar el deíctico "aquî", દ̉v $\theta \alpha ́ \delta \varepsilon$; sino que había abandonado su patria. En el último verso, se lamenta de no poder ver a sus padres, quienes, suponemos, se quedaron en su lugar de origen, pues le

35 Literalmente, este verbo significa "alegrarse", por lo que en segunda persona del plural sería "alegraos" o "alégrense". Tradicionalmente se puede traducir como "salud" o "saludos". 
sobrevino la muerte. Este tercer verso inicia con una predicación de él

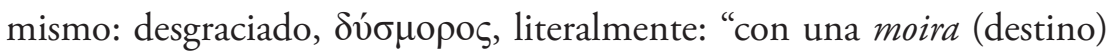
adversa", esto recuerda la idea inevitable y nada agradable de la muerte, detallada anteriormente. El epitafio no menciona cómo murió, al parecer no cumplió con su deber en ese sitio, ya que no hay ninguna cualidad mencionada, sólo la referencia a su muerte como desgracia.

En el primer verso, en tercera persona, el emisor y el receptor son el lector, se hace una presentación de la tumba. En los siguientes dos versos, en primera persona, el emisor es el difunto, ya con la atención del caminante, se dirige a él y se queja de su destino. En este epigrama es muy clara la intención de representar un contacto oral, un acto de habla.

Como se observa, los epigramas que tienen como eje el lugar (no el tiempo) hablan de la trascendencia de que los difuntos estén enterrados precisamente en ese lugar, Atenas, y no tanto de la tristeza o pena que dejaron a los vivos. Además, algunos contraponen dicha ciudad con el más allá.

En conclusión, los elementos deícticos tienen una función especial en los epigramas funerarios áticos de época clásica, debido a que, desde su creación, fueron pensados como actos de habla, situaciones comunicativas prácticamente orales, donde había un emisor, un receptor y una intención en el mensaje. Dicho acto de habla se repetía, se representaba o se recreaba, cada vez que alguien los leía.

Estos elementos deícticos se volvieron tan importantes que muchos epigramas se pueden analizar a partir de los dos ejes presentados en este texto: el temporal y el local, esto pone énfasis en lo importante que resultaba el ahora y el aquí para la cultura griega clásica: la mujer y el hombre debían tener cualidades y realizar acciones reconocidas en vida por la sociedad, sólo así obtendrían alabanzas y fama, las cuales trascenderían la muerte. Una vía para hacerlas eternas era precisamente a través de estos epigramas funerarios. 
Resulta interesante que los epitafios que tienen como eje el tiempo, con el adverbio ahora, vĩv, muestran más tristeza y pena en quienes sobreviven a los difuntos, así como la posibilidad de que el alma disfrute de una existencia en el más allá, acorde a su conducta en vida. En cam-

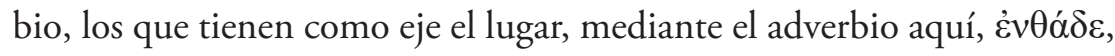
más bien remarcan quién fue el difunto y sus cualidades en vida, para argumentar por qué fue digno de un entierro en Atenas, ciudad tan importante en la época clásica.

Tras examinar ocho epigramas funerarios áticos de la época clásica esperamos contribuir a su total comprensión y, por ende, subrayar la importancia de volver los ojos a estos testimonios que, implícita o explícitamente, son claro reflejo del pensamiento y las creencias de la sociedad que los produjo. 


\section{Referencias}

Arteaga, Evelia. “¿Cómo 'habla’ el epigrama funerario ático? Una relación entre vivos y muertos". Nova Tellvs 37/2 (julio-diciembre 2019), 49-65.

Bernabé, Alberto. “The Gods in Later Orphism”. En Jan N. Bremmer Andrew Erskine, editores. The Gods of Ancient Greece. Edimburgo: Edinburgh University Press, 2010. 422-441. . y Ana Isabel Jiménez. Instrucciones para el más allá. Las laminillas órficas de oro. Madrid: Ediciones Clásicas, 2002.

- y Francesc Casadesús, coordinadores. Orfeo y la tradición órfica. Un reencuentro I y II. Madrid: Akal, 2008.

Bing, Peter. "The Un-Read Muse? Inscribed Epigram and Its Readers in Antiquity”. En M. A. Harder y otros, editores. Hellenistic Epigrams. Lovaina: Peeters, 2002, 39-66. Citado en: Regina Höschele. "The Traveling Reader: Journeys through Ancient Epigram Books". Transactions of the American Philological Association, 137, núm. 2 (otoño 2007). 333-369.

Burns, Alfred. "Athenian Literacy in the Fifth Century B. C.". Journal of the History of Ideas vol. 42, núm. 3 (julio-septiembre 1981): 371-387.

Burton, Diana. "Public Memorials, Private Virtues: Women on Classical Athenian Grave Monuments". Mortality vol. 8, núm. 1 (2003), 20.

Carmina Epigraphica Graeca vol. 2, Saeculi Iv a.Chr.n. Petrus Allanus Hansen, editor. Berlín: De Gruyter, 1989.

Del Barrio Vega, María Luisa. "Función y elementos constitutivos de los epigramas funerarios griegos”. En Estudios Clásicos, tomo 31, núm. 95 (1989). 10-11. , editora. Epigramas funerarios griegos. Madrid: Gredos, 1992. 
Díaz de Cerio, Mercedes. "Estructura discursiva en el epigrama funerario: la evolución de un género". Habis 30 (1999). 189-204.

Escandell Vidal, M. Victoria. Introducción a la pragmática. Madrid: Universidad Nacional de Educación a Distancia, 1993.

Fraser, Peter Marshall. Greek Ethnic Terminology. Oxford: Oxford University Press, 2009.

Ginestí, Rosell, Anna. "Presencia de extranjeros en Atenas a partir de las inscripciones funerarias: el epigrama en honor de Pitágoras de Selimbria (IG I 1154)". En Actas del XI Congreso de la Sociedad española de estudios clásicos, II. Madrid: Sociedad Española de Estudios Clásicos, 2005. 303-310.

. "Las inscripciones funerarias como fuente de información sobre el estatus socio-jurídico de las mujeres extranjeras en Atenas". Actas del XII Congreso Español de Estudios Clásicos, I. Madrid: Sociedad Española de Estudios Clásicos, 2009. 763-772.

. "Próxenos, métoikos, isotelés. La integración de extranjeros en Atenas". Faventia Supplementa 2. Contacto de poblaciones y extranjería en el mundo griego antiguo, Barcelona: Universitat Autònoma de Barcelona 2013. 287-302.

. "Mujeres extranjeras en los epitafios atenienses". Faventia Supplementa 2. Contacto de poblaciones y extranjería en el mundo griego antiguo, Barcelona: Universitat Autònoma de Barcelona, 2013. 319-337.

Harris, William V. Ancient Literacy. Cambridge: Harvard University Press, 1989.

Havelock, Eric A. Preface to Plato. Cambridge: Harvard University Press, 1963.

Heródoto. Historia, traducción de Manuel Balasch, quinta edición. Madrid: Cátedra, 2007. 
Homero. Odisea, traducción de José Manuel Pabón, introducción de Carlos García Gual. Madrid: Gredos, 2007.

Johnson, William A. y Holt N. Parker, editores. Ancient Literacies. The Culture of Reading in Greece and Rome. Oxford: Oxford University Press, 2009.

López, Ángel y otros. Lingüistica general y aplicada. Valencia: Universidad de València, 1999.

Lougovaya-Ast, Julia. "An Historical Study of Athenian Verse Epitaphs from the Sixth through the Fourth Centuries BC”. Tesis de Ph.D., Toronto: University of Toronto, 2004.

Lyons, John. Semántica lingüistica. Una introducción. Barcelona, Buenos Aires y México: Paidós, 1997.

Martín López, Isabel. "Deixis frente a anáfora en griego antiguo". Minerva. Revista de filología clásica 8, 1994,11-41.

Miller, Fred D. Jr. "Philosophical Themes in Early Greek Grave Inscriptions”. XI Congresso Internazionale di Epigrafia Greca e Latina. Roma, 18-24 septiembre de 1997. Atti I. Roma: Edizioni Quazar, 1999. 194-198.

Platón. República. En Diálogos $I V$, traducción de Conrado Eggers Lan. Madrid: Gredos, 1986.

Scodel, Ruth. "Inscription, Absenceand Memory:Epicand Early Epitaph". Studi italiani di Filologia Classica, LXXXV annata, terza serie, volume X, fascicoli I-II. Florencia: Felice Le Monnier, 1992.

Sourvinou-Inwood, Christiane. "Male and Female, Public and Private, Ancient and Modern". En Pandora: women in classical Greece, Ellen D. Reeder, ed. Baltimore, Md., Princeton, N.J: Trustees of the Walters Art Gallery, Princeton University Press 1995.

Svenbro, Jesper. Phrasikleia: Anthropologie de la lecture en Grèce ancienne. París: Editions La Découverte, 1988.

Tsagalis, Christos C. Inscribing Sorrow: Fourth-Century Attic Funerary Epigrams, vol. 1. Berlín y Nueva York: Walter de Gruyter, 2008. 
Tueller, Michael A. "The Passer-by in Archaic and Classical Epigram”. Manuel Baumbach, Andrej Petrovic, Ivana Petrovic, editores. Archaic and Classical Greek Epigram. Nueva York: Cambridge University Press, 2010. 42-60.

Vestergaard, Torben. "Bárbaros y otros extranjeros en el Atenas clásica: el testimonio de los epitafios”, traducción de Patricia Villaseñor C. Nova Tellus 21-1 (2004). 